\title{
Survey on Temporal Patterns in Physiological Sensor Data
}

\begin{abstract}
Nilam
Abstract: In past few years development of wearable sensors for health monitoring systems has garnered lots of attention in the scientific community and the industry. A mining system can predict the future health status of the patient based on the temporal trajectories of health status of number of similar patients. The wearable sensor technology increases the attention in both clinical and at home settings, the accumulation of physiological sensor data requires a concentrated effort on the analysis and modeling of this data. Main aspect of study in such system is how the data is treated and processed. Many paper overviews the more common data mining tasks that have been applied such as anomaly detection, prediction and decision making when considering in particular continuous time series measurements. This paper attempts to comprehensively review the current research and development on wearable sensor systems for health monitoring. And also latest methods and algorithms used to analyze data from wearable sensors used for physiological monitoring of vital signs in healthcare services. There is need of more efficient and correctly functioning method for mining data from wearable sensors.
\end{abstract}

Keywords: data mining, wearable sensors, physiological sensors, health monitoring system.

\section{Introduction}

Now a days, the research area of health monitoring systems has shifted from simple reasoning of wearable sensor readings to the higher level of data processing in order to give much more information that is important to the end users. Wearable health-monitoring systems have drawn a lot of interest from the research community and the industry during the last few years. Wearable systems for health monitoring may contain various types of miniature sensors, wearable or even implantable. The main objective of data mining in healthcare monitoring systems is to retrieve information and there are several tasks considering wearable sensors that data mining methods are able to carry out. In last few years, temporal association rule mining methods have been applied on clinical data stream to recognize complex relationships of the physiological sensor observations. Data-driven methods capable to discover hidden and potentially useful information through the physiological sensor data and to construct models based on the experimental data.

There has been a need to monitor a patient's health status while he is out of the hospital in his personal environment. The remaining paper can be summed as: section 2 studies some previously developed methods and algorithms used to analyze data from wearable sensors used for physiological monitoring of vital signs in healthcare services. Section 3 concludes our paper.

\section{Literature Survey}

In [2], author proposed novel scheme to generate the rules from the data collection using subtractive clustering and fuzzy inference Tagaki Sugeno Kang orde-1 method. The method is a clustering algorithm to look for data clusters that serve as the fuzzy rules for diagnosis of CHD risk and selected cluster number is determined based on the value of variant boundaries. Proposed approch present benefits, method is applicable to generate the fuzzy rules without defining and describing from an expert.
In [3], paper presents an approach to automatically mine rules in time series data representing physiological parameters in clinical conditions considering the individualization of clinical conditions. In this paper, a method for measuring uniqueness of rule sets is introduced in order to authenticate the similarity of rule sets. The proposed approach considers 9 clinical conditions such as angina, sepsis, and respiratory failure, along three physiological measurements. This method is estimated on physiological records from clinical classes in the MIMIC online database such as angina, sepsis, respiratory failure. To avoid processing incorrect information, the data with unreliable values are ignored and also a smoothing function is applied on data to flatten the noisy data.

In [4], present a mining system that can guess the future health status of the patient using the temporal trajectories of health status of a set of similar patients. Proposed approach and system were tested using the MIMIC II database. It consists of physiological waveforms, and accompanying clinical data obtained for ICU patients. Proposed approach acheived efficiency and throughput of the stream processing unit for feature extraction, and also the accuracy of the temporal projections of the patient data.

In [5], author introduced the problem of mining association rules between sets of items in a large database of customer transactions. Author present an efficient algorithm that generates all significant association rules between items in the database. Proposed algorithm includes buffer management and novel estimation and pruning techniques. Effectiveness of algorithm is measured by applying this algorithm to sales data obtained from a large retailing company.

In [6], author proposed a novel warping distance, namely Spatial Assembling Distance (SpADe), that is capable to handle shifting and scaling in both temporal and amplitude dimensions. Proposed an efficient approach for continuous pattern detection based on SpADe. Proposed distance SpADe tries to handle both shifting and scaling in temporal and amplitude dimensionsof time series. Benefits of SpADe 


\section{International Journal of Science and Research (IJSR) \\ ISSN (Online): 2319-7064 \\ Index Copernicus Value (2013): 6.14 | Impact Factor (2014): 5.611}

are effective and efficient for continuous pattern detection in streaming time series.

In [7], author presented a novel algorithm for extracting rules expressing complex patterns from temporal data in both the antecedent and the consequent, which can be used in a numerous biomedical domains. The author presents the results obtained by the rule extraction algorithm in two different biomedical applications. The first domain is the analysis of time series coming from the monitoring of hemodialysis sessions, while the other deals with the biological problem of inferring regulatory networks from gene expression data.

\begin{tabular}{|c|c|c|c|c|}
\hline $\begin{array}{l}\text { Sr. } \\
\text { No. }\end{array}$ & Paper & Technique & Advantages & Disadvantages \\
\hline 1 & $\begin{array}{c}\text { Fuzzy rule generation for } \\
\text { diagnosis of coronary heart } \\
\text { disease risk using substractive } \\
\text { clusteringmethod } \\
{[2]}\end{array}$ & $\begin{array}{l}\text { Proposed novel scheme to } \\
\text { generate the rules from the } \\
\text { data collection using } \\
\text { subtractive clustering and } \\
\text { fuzzy inference Tagaki } \\
\text { Sugeno Kang orde-1 method }\end{array}$ & $\begin{array}{c}\text { Proposed approch present } \\
\text { benefits, method is applicable to } \\
\text { generate the fuzzy rules without } \\
\text { defining and describing from an } \\
\text { expert. }\end{array}$ & $\begin{array}{l}\text { If the system has never } \\
\text { made the process the } \\
\text { formation of fuzzy rules, } \\
\text { then the user can't do the } \\
\text { testing on the system. }\end{array}$ \\
\hline 2 & $\begin{array}{l}\text { Descriptive modelling of } \\
\text { clinical conditions with data- } \\
\text { driven rule mining in } \\
\text { physiological data [3] }\end{array}$ & $\begin{array}{l}\text { Paper presents an approach to } \\
\text { automatically mine rules in } \\
\text { time series data representing } \\
\text { physiological parameters in } \\
\text { clinical conditions } \\
\text { considering the } \\
\text { individualization of clinical } \\
\text { conditions }\end{array}$ & $\begin{array}{l}\text { To avoid processing incorrect } \\
\text { information, the data with } \\
\text { unreliable values are ignored and } \\
\text { also a smoothing function is } \\
\text { applied on data to flatten the } \\
\text { noisy data. }\end{array}$ & $\begin{array}{c}\text { semantic modelling } \\
\text { based on the rule sets and } \\
\text { characterising the } \\
\text { semantic model to improve } \\
\text { the quality of text is limited } \\
\text { in this paper. }\end{array}$ \\
\hline 3 & $\begin{array}{c}\text { SpADe: On Shape-based } \\
\text { Pattern Detection in Streaming } \\
\text { Time Series [4] }\end{array}$ & $\begin{array}{l}\text { Author present a mining } \\
\text { system that can guess the } \\
\text { future health status of the } \\
\text { patient using the temporal } \\
\text { trajectories of health status of } \\
\text { a set of similar patients. }\end{array}$ & $\begin{array}{l}\text { Proposed approach acheived } \\
\text { efficiency and throughput of the } \\
\text { stream processing unit for feature } \\
\text { extraction, and also the accuracy } \\
\text { of the temporal projections of the } \\
\text { patient data. }\end{array}$ & \\
\hline 4 & $\begin{array}{c}\text { Mining association rules } \\
\text { between sets of items in large } \\
\text { databases [5] }\end{array}$ & $\begin{array}{l}\text { Author present an efficient } \\
\text { algorithm that generates all } \\
\text { significant association rules } \\
\text { between items in the } \\
\text { database. }\end{array}$ & $\begin{array}{l}\text { Effectiveness of algorithm is } \\
\text { measured by applying this } \\
\text { algorithm to sales data obtained } \\
\text { from a large retailing company. }\end{array}$ & $\begin{array}{l}\text { It is possible that the } \\
\text { current itemset that caused } \\
\text { the memory shortage is the } \\
\text { one having maximum } \\
\text { number } \\
\text { of items. }\end{array}$ \\
\hline 5 & $\begin{array}{c}\text { Spade: On } \\
\text { shape-based pattern detection } \\
\text { in streaming time series [6] }\end{array}$ & $\begin{array}{c}\text { Author proposed a novel } \\
\text { warping distance, namely } \\
\text { Spatial Assembling Distance } \\
\text { (SpADe), that is capable to } \\
\text { handle shifting and scaling in } \\
\text { both temporal and amplitude } \\
\text { dimensions }\end{array}$ & $\begin{array}{l}\text { SpADe is effective and efficient } \\
\text { for continuous pattern detection } \\
\text { in streaming time series. }\end{array}$ & $\begin{array}{l}\text { It does not consider } \\
\text { how to partition the } \\
\text { steaming time series and } \\
\text { how to } \\
\text { efficiently find matching } \\
\text { subsequences }\end{array}$ \\
\hline
\end{tabular}

\section{Conclusion}

This paper presented an all-inclusive survey of the current research and development on wearable sensor systems for health monitoring. And also latest methods and algorithms used to analyze data from wearable sensors used for physiological monitoring. The main features, the advantages and disadvantages different techniques that has been developed and used in past years. This paper reviewed the state-of-the-art in research and development of wearable sensor-based systems for health monitoring.

As per survey, strong need to focus on Physiological Sensor Data due to increase in attention. We proposed a new method to overcome the drawbacks of the previous methods available for data mining.

\section{References}

[1] Hadi Banaee and Amy Loutfi, "Data-Driven Rule Mining and Representation of Temporal Patterns in
Physiological Sensor Data", IEEE JOURNAL OF BIOMEDICAL AND HEALTH INFORMATICS, VOL. 19, NO. 5, SEPTEMBER 2015.

[2] L. Muflikhah and Y. Wahyuningsih, "Fuzzy rule generation for diagnosis of coronary heart disease risk using substractive clusteringmethod," Softw. Eng. Appl., vol. 6, pp. 372-378, 2013.

[3] H. Banaee, M. U. Ahmed, andA. Loutfi, "Descriptive modelling of clinical conditions with data-driven rule mining in physiological data," in Proc. Int. Conf. Health Informat., 2015, pp. 103-113.

[4] Yueguo Chen, Mario A. Nascimento, Beng Chin Ooi and Anthony K. H. Tung,"SpADe: On Shape-based Pattern Detection in Streaming Time Series".

[5] R. Agrawal, T. Imieli'nski, and A. Swami, "Mining association rules between sets of items in large databases," in Proc. ACMSIGMOD Rec.,1993, vol. 22, no. 2, pp. 207-216.

[6] Y. Chen, M. A. Nascimento, B. C. Ooi, and A. K. Tung, "Spade: On shape-based pattern detection in streaming time series," in Proc. IEEE Data Eng., 2007, pp. 786795.

\section{Volume 4 Issue 12, December 2015}




\section{International Journal of Science and Research (IJSR) \\ ISSN (Online): 2319-7064}

Index Copernicus Value (2013): 6.14 | Impact Factor (2014): 5.611

[7] T. Schluter and S. Conrad, "About the analysis of time series with temporal association rule mining," in Proc. IEEE Symp. Comput. Intell. Data Mining, 2011, pp. 325-332.

[8] P.-N. Tan, M. Steinbach, and V. Kumar, Introduction to Data Mining. Boston, MA, USA: Addison-Wesley, 2006, vol. 1.

[9] S. Kotsiantis and D. Kanellopoulos, "Association rules mining: A recent overview," GESTS Int. Trans. Comput. Sci. Eng., vol. 32, pp. 71-82, 2006.

[10] M. Ohsaki,Y. Sato,H.Yokoi, and T.Yamaguchi, “Arule discovery support system for sequential medical data, in the case study of a chronic hepatitis dataset," in Proc ECML/PKDD Discovery Challenge Workshop, 2002, pp. 154-165. A. L. Goldberg. 